\title{
THE DICKINSON MEMORIAL LECTURE
}

\begin{abstract}
$\mathrm{T}$ HE first biennial Dickinson Memorial Lecture to the Newcomen Society for the Study of the History of Engineering and Technology was delivered by Dr. Charles Singer on May 12-most appropriately, in the lecture theatre of the Science Museum, South Kensington, where the late Dr. Henry Winram Dickinson (1870-1952) was keeper of the mechanical engineering collections for a number of years prior to his retirement in 1930. The president of the Society, Mr. Rex Wailes, in introducing the lecturer, recalled that he had been an intimate friend of Dr. Dickinson almost since the inception of the Society in 1920. Dickinson, a founder member, had been its honorary secretary from its foundation until 1951 except for the two years (1932-34) of his presidency and had personally edited the first twenty-five volumes of its Transactions.

The title of the lecture had been announced as "The New Era in the History of Technology"; but, as Dr. Singer said, he would prefer to call it "The Happy Scholar", for that description was typical of Dickinson's life and character. $\mathrm{He}_{e}$ was born in Ulverston, the eldest son of the secretary of a steel firm, and was educated in Manchester at the Grammar School and at Owens College. After a short period in the steel industry, he was appointed a junior assistant at the Science Museum, where he spent thirty-five years. The most significant events of his service there were the acquisition and arrangement of some of the more important historical exhibits, notably the early Watt engines and the contents of James Watt's garret workshop. His greatest work, however, is to be found in the volumes of the Transactions of the Newcomen Society. These, Dr. Singer prophesied, would be regarded for many generations as the foundation of a new discipline in the study of
\end{abstract}

history and as a first sign of the broadening of technical education; for, before the advent of the Society, there was no English medium for the communication of ideas or the publication of conclusions on the history of the useful arts, nor any library, other than that of the Patent Office, which had attempted to put together any collection of works on the history of technology.

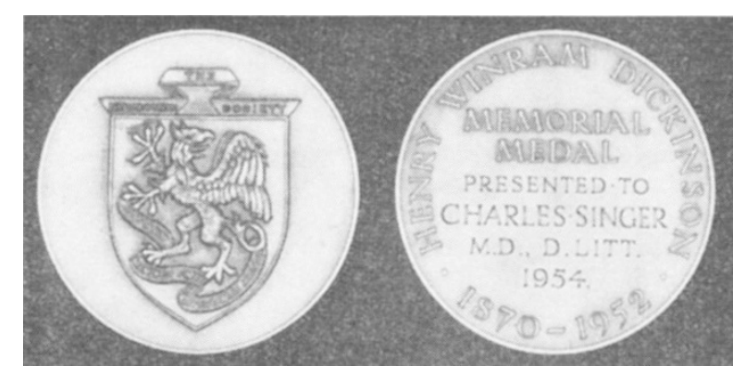

On the conclusion of the lecture, Mr. Wailes presented to Dr. Singer a bronze commemorative medal, bearing on its obverse the badge of the Society (a gryphon segreant, with the motto, Actorum memores simul affectamus agenda) and on the reverse, "Henry Winram Dickinson 1870-1952" and the inscription, "Presented to Charles Singer M.D., D.Litt. 1954". A vote of thanks to the lecturer was proposed by Dr. A. P. Thurston, a former president of the Society and a co-founder with Dickinson, seconded by Mr. Arthur Stowers, the present keeper of the mechanical engineering collections at the Science Museum, and supported by Dr. S. B. Hamilton.

\section{THIRD INTERNATIONAL BIOMETRIC CONFERENCE}

\begin{abstract}
THE Biometric Society, which now has nearly 1,200 members in fifty countries, held its third international conference in Bellagio, Italy, during September 1-5, under the presidency of Prof. G. Darmois, of Paris. The methods of biometry are coming to be used in an ever-wider variety of fields of application, and this variety was reflected in the papers presented during the week.

The Society has always interested itself in the teaching of biometry and a session was devoted to this topic, with speakers from Belgium, France, Italy and the United States. The basic problem is that of teaching a subject which is essentially mathematical to students who are at best uninterested in mathematics. C. I. Bliss (New Haven) has been giving an introductory course to biologists for some years, and he presented the replies to a questionnaire that he had circulated among his old students. Their comments were outspoken, but most of them had found the course a useful one, particularly since it
\end{abstract}

enabled them to get the full benefit of expert statistical advice.

Geneticists were well represented at the conference which followed immediately after the International Genetical Congress. K. Mather (Birmingham), D. Lowry (Berkeley), J. L. Lush (Ames) and C. A. B. Smith (London) all gave papers on quantitative inheritance. This topic is of great importance in modern genetical research, and the appropriate methods of collecting and analysing data were the subject of considerable discussion. Even the basic concepts, such as heritability, are not unequivocally defined, as was pointed out by J. L. Lush, and their use and interpretation in the practical breeding of animals and plants are full of pitfalls. Up to date, most statistical work has been based on models assuming additive and independent genetic effects, and the extension of such research to more realistic models is a matter of great importance. Without some guidance from a set of fruitful hypotheses, it is 
difficult to set up experiments which will provide the right kind of information on which to base further progress.

In the session on biometric methods in agriculture, much of the discussion concerned methods of agronomic experimentation in under-developed regions such as India, where large regions have to be covered and where information on fertilizer responses, etc., is largely lacking. V. G. Panse (New Delhi) described work going on at present in India, and $\mathrm{F}$. Yates (Rothamsted) gave a general discussion of the planning of experiments on cultivator's fields, involving only $4-6$ plots. During the past twenty years more and more elaborate experimental designs have been developed to fit the requirements of single experiments of high precision, but the need exists for the planning of large numbers of very small experiments which will provide useful information over a wide area. They must be extremely simple to avoid errors in laying them out and should, if possible, also serve as demonstrations. Factorial arrangements with fractional replication are useful, but may need some adaptation to meet local conditions.

In the session on methodological problems, F. J. Anscombe (Cambridge) reported on the analysis of sequentially obtained observations by methods assuming fixed sample size. $\mathrm{He}$ showed that the ordinary methods of analysis give very good approximations to the truth in most ordinary circumstances, though it is easy to construct examples where they produce quite false results. A paper by M. Keuls (Wageningen) gave rise to a lively discussion at a later session. This dealt with testing the differences between means in an analysis of variance. In a variety trial, for example, the ordinary $F^{\prime}$-test will show whether the whole set of varietal means are or are not significantly different, but the investigation of individual differences is less straightforward. Much work on this problem has been going on in the United States (Duncan, Tukey, Scheffé, etc.). The discussion showed a rather considerable cleavage of opinion, some speakers considering that the provision of exact significance tests for individual differences was of great importance, others that significance testing was largely irrelevant in variety trials, since a large enough experiment would show that all the varieties in the trial were significantly different. This question was related to a paper by M. J. R. Healy (Rothamsted), reporting on an investigation by P. M. Grundy which dealt with the fixing of the number of experiments needed to decide between two alternatives. In this investigation, the concept of significance did not arise, the economic amount of experimentation being arrived at by balancing the cost of the experiments against the loss resulting from an incorrect decision.

Most of the papers briefly mentioned above together with other contributions to the conference will be published in Biometrics this year. The organization of the meetings was in the hands of the Italian section of the Biometric Society, and great praise is due to the local secretary, Dr. L. L. CavalliSforza (Milan), who was both ubiquitous and multilingual. Biometry, more than most disciplines, is full of local problems the solution of which is valuable both as theory and in practice, but which are frequently ignored for the want of adequate technical equipment. The posing and discussion of such problems, not only during the formal sessions, was not the least valuable part of the conference.

M. J. R. HEALY

\section{GAS ABSORPTION} SYMPOSIUM IN BIRMINGHAM

A SYMPOSIUM on gas absorption, organized by the Institution of Chemical Engineers, was held in the University of Birmingham during April 5-7, and eighteen papers were read dealing with theoretical concepts and laboratory data and with the efficiency of various types of absorbent and of different forms of absorption equipment. The conference was attended throughout the four sessions by more than two hundred people, and a lively discussion included a debate on the mechanics of absorption, particularly those where physical absorption is accompanied by chemical reaction.

J. W. Griler, F. Goodridge and D. B. Atkin presented equilibrium and rate data for the absorption of carbon dioxide under static conditions by aqueous solutions of Abrac lye, monoethanolamine, a 50 per cent mixture of methyldiethanolamine in diethanolamine and $\mathrm{N}$-amino ethyl morpholine. The last two materials were rejected as impracticable absorbents. These workers measured rates during the initial period of contact between gas and liquid, and also rates during longer contact periods. Absorption-rate was proportional to the partial pressure of carbon dioxide.

G. Edwards, R. Robertson, F. Rumford and J. Thomson have studied the absorption of carbon dioxide by liquid jets of ammoniacal solutions and have found that the rate of transfer increases with decreasing jet length and, in contrast to the paper of J. W. Gailer, F. Goodridge and D. B. Atkin, the rate is independent of the partial pressure of carbon dioxide. Experiments on cooling and dehumidifying air with refrigerated brine, using a grid-packed tower, were described by W. S. Norman, M. O. Algawi and F. H. Garner for a range of gas-and liquid-rates. The somewhat high liquid-film 'heights of a transfer unit' (2-5 ft.) may be due to the high viscosity of the brine (3-4 centipoises). A considerable brine film resistance was inferred.

D. Hammerton and F. H. Garner presented experimental data on the rate of solution of single gasbubbles rising in water, for which a technique was developed for measuring changes of $10^{-3} \mathrm{ml} / \mathrm{sec}$. in bubble size due to solution. Five gases were used in water and glycerol. Comparison between experimental results and theoretical predictions for rigid and for circulating spheres indicated that bubbles circulate freely at diameters greater than $0.4 \mathrm{~cm}$. Surface-active contaminants reduced the transferrate to that predicted for rigid spheres. A novel expression for the gas film mass transfer coefficient, $K_{g}$, was proposed by $\mathrm{S}$. Bakowski, from kinetic considerations :

$$
K_{g}=\frac{1.0 \times 10^{-6}(v+60)}{M^{1 / 2} P^{1 / 3}} \text { gm.-mol./cm. }{ }^{2} \text { sec. atm., }
$$

where $v$ is the gas velocity (cm./sec.), $P$ the total pressure (atm. abs.) and $M$ the molecular weight of the gas. Good agreement was obtained with data on evaporation from plane liquid surfaces and on absorption, evaporation and distillation in falling-film towers.

In the first of two papers by P. V. Danckwerts and A. M. Kennedy, three models of the liquid film absorption process - those of W. G. Whitman, R. Higbie and P. V. Danckwerts-were compared; 